\title{
Knowledge, Attitude, and Practice of General Public Towards COVID-19 in India: An Online Cross-Sectional Study
}

\author{
Aastha Singh ${ }^{1}$, Rakhi Ahuja ${ }^{2}$ \\ M.P.H.Student, School of Allied Health Sciences, Delhi Pharmaceutical Sciences and Research University, New Delhi, \\ India $^{1}$ \\ Assistant Professor, School of Allied Health Sciences, Delhi Pharmaceutical Sciences and Research University, New \\ Delhi, India ${ }^{2}$
}

\begin{abstract}
Background: Coronavirus disease 2019 (COVID-19) is a rapidly spreading infectious disease that had been announced pandemic by the World Health Organization. This study aims to measure the level of knowledge, attitude, and practice of the general public towards COVID-19 in India, and to detect the association with sociodemographic variables.

Methods: A cross-sectional study, conducted on the general population of India. A survey questionnaire included socio-demographic characteristics and 24 item questions on knowledge, attitude, practice towards Coronavirus disease 2019 (COVID-19). The questionnaire was made in both Hindi and English for a better understanding of participants. Data were collected online through survey forms and analyzed.

Results: The questionnaire was completed by 694 participants, $63.5 \%$ of the participants had good knowledge about COVID-19. Knowledge, attitude and practice scores were significantly similar for both males and females. Regarding the attitude, $74 \%$ of the participants had a positive attitude and $90 \%$ of the participants considered COVID-19 as a serious disease. $93.2 \%$ of the participants in our study had adopted practices to prevent COVID-19. Moreover, 99\% of the participants followed social distancing in their daily routine.

Conclusion: The overall population had good knowledge, positive attitude, and have adopted the practices to prevent the disease during the pandemic. People with low knowledge about COVID-19 need to be targeted, to promote their positive attitude and to adopt safe practices.
\end{abstract}

KEYWORDS:COVID-19, Knowledge, Attitude, Practice, India.

\section{INTRODUCTION}

Coronavirus disease 2019 (COVID-19) is an infectious disease caused by a novel strain of Coronavirus (2019-nCoV). During the end of December 2019, the initial cases of COVID-19 emerged in Wuhan City, Hubei Province of China [1]. The COVID-19 had spread rapidly from its origin in Wuhan, China to the rest of the world due to which the outbreak was declared public health emergency of international concern by the World Health Organization (WHO) on January 30th, 2020 [2]. There were 125,260 cases of COVID-19 around the world on March 12th, 2020 and the virus had reached 118 countries, and the WHO characterized this situation as a global pandemic [3]. As of June 14th, 2020, there were 7,553,182 confirmed cases in the world and 308,993 confirmed cases in India, and the death toll has reached 423,349 and 8,884 respectively [4]. India stands at the fourth position with the greatest number of confirmed cases so far [5].

COVID-19 is the first coronavirus after Spanish Flu (1918 to1919), which has extremely influenced the health system, economy, and psychology of India [6]. The threat of COVID-19 is increasing day by day as the cases are not in control.Implementing personal hygiene and health behaviors are necessary to curb the spread of coronavirus, such as hand washing and social distancing [7]. Without sustained bans on large gatherings including large weddings, mass prayers, and funeral, these may create super-spreading events that accelerate transmission [8].

The recommended control measures need to be adopted by the citizens of India and its effectiveness is influenced by their knowledge, attitudes, and practices (KAP) towards COVID-19 as per KAP theory [9]. The time required for the development of vaccines is unknown, and thus control of this situation depends upon the effective implementation of control measures. 


\author{
||Volume 9, Issue 6, June 2020\|
}

Lessons learned from the severe acute respiratory syndrome (SARS) outbreak in 2003 suggest that knowledge and attitudes towards infectious diseases are associated with the level of panic emotion among the population, which can further complicate attempts to prevent the spread of the disease [10]. Behaviors like underestimation, stigmatization, panic emotions, false measures to avoid infection affect the battle against such an uncommon situation [11].

The future course of this virus is unknown. In the initial stage of the pandemic, India reported some of the lowest infection rates of COVID-19. Numbers began to rise in late March 2020, with confirmed cases increasing across the country, however, this number may reflect a shortage of tests [12].

The present study aimed to measure the level of knowledge, attitude, and practice of the general public towards COVID-19 in India, and to detect the association with sociodemographic variables.

\title{
II. METHODOLOGY
}

\section{Study design and Population:}

This study was a web-based cross-sectional survey. The sample size was determined using the Epi Info 7 software. The sample size was estimated by assuming that the probability of having a good knowledge and positive attitude towards preventive measures against coronavirus disease was 50\%, confidence level $=99 \%$, and d (margin of error) $=5 \%$. The calculated sample size of this study was 665 participants. The inclusion criteria consisted of participants of Indian nationality aged 18 years and above.

\section{Questionnaire preparation:}

The questionnaire of this study was developed with the help of WHO training material for COVID-19 [13]. A 24-item survey questionnaire was prepared in both Hindi and English for a better understanding of the participants. The questionnaire was comprised of socio-demographic characteristics, knowledge regarding COVID-19, attitude towards COVID-19, and practice regarding the prevention of COVID-19.Socio-demographic characteristics included questions related to age, gender, marital status, education, employment status, income, and place of current residence. Place of residence was further compressed into five zones North zone, South zone, East zone, West zone, and Central zone.

\section{Knowledge about COVID-19:}

The knowledge section of the questionnaire consisted of 13 questions (K1-K13): 6 questions regarding clinical presentations (K1-K6), 4 questions regarding prevention and control (K7-K10), and 3 questions regarding transmission routes (K11-K13) of COVID-19. A correct answer was assigned one point and an incorrect/unknown answer was assigned zero points. Thus, total knowledge scores ranged from 0 to 13 , with a higher score denoting a better knowledge of COVID-19. Knowledge score was interpreted in terms of Good, Fair, and Poor, where a score of more than 10 denoted good knowledge, between 6 to 10, denoted fair knowledge, and less than 6 denoted poor knowledge.

\section{Attitude towards COVID-19:}

To evaluate the attitude of the general public towards COVID-19, 4 questions were asked (A1-A4). The scoring was similar to the knowledge section. The total attitude score ranged from 0 to 4 .

\section{Practice regarding COVID-19:}

There were 7 questions related to practice (P1-P7) for the prevention of COVID-19. The scoring systems for practice were similar to the knowledge section. The total practice score ranged from 0 to 7 . These questions were answered on the Yes/No basis.

\section{Data Collection:}

Data was collected using Google Form and the link was distributed through the various social media platforms. Participants were encouraged to share the google form link with their friends and relatives. A short description of the study, voluntary participation, declaration of confidentiality, and anonymity were included at the beginning of the form. The data were collected from 23rd May to 1st June 2020 and the questionnaire was completed by 704 participants.

\section{Statistical Analysis:}

Data were coded and recorded in the MS Excel spreadsheet program. For data analysis, Statistical Package for the Social Sciences (SPSS) software, version23(IBM Corp.) was used. Descriptive statistical methods were utilized to summarize data on socio-demographic characteristics and responses to the knowledge, attitude, and practice (KAP) questions towards COVID-19.Descriptive statistics were elaborated in the form of means/standard deviations and medians/Interquartile range (IQRs) for continuous variables, and frequencies and percentages for categorical variables. Group comparisons for continuously distributed data were made using independent sample ' $t$ ' test when comparing two groups. If data were found to be non-normally distributed, appropriate non-parametric tests in the form of the Wilcoxon test were used. A chi-square test was used for group comparisons for categorical data. In case the expected frequency in the contingency tables was found to be $<5$ for $>25 \%$ of the cells, Fisher's Exact Test was used instead.

Linear correlation between two continuous variables was explored using Pearson's correlation (if the data were normally distributed) and Spearman's correlation (for non-normally distributed data). Statistical significance was kept at $\mathrm{P}<0.05$. 
Ethical Considerations:

This study was approved by the ethics committee of the institution. Respondent's anonymity and confidentiality were ensured. At the beginning of the questionnaire, consent was sought in terms of yes or no for willingness to participate.

\section{RESULTS}

The questionnaire was filled by 704 participants, out of which 10 participants did not consent to participate thus a final sample of the study was 694 participants. More than half of the participants $(64.4 \%)$ were between 18 to 30 years of age. Distribution of participants based on gender was somewhat equal, for males and females i.e. $49.3 \%$ and $50.6 \%$ respectively. Over one-half of the participants were unmarried. The least number of responses were from the South and West zone of the country. (Table 4)

Table 1: Summary of knowledge, attitude and practice assessment on COVID-19 among the general population of India (n = 694)

\begin{tabular}{|c|c|c|}
\hline \multirow{2}{*}{ Knowledge, Attitude and Practice Items } & \multicolumn{2}{|c|}{ Frequency $(\%)$} \\
\hline & Correct & Incorrect \\
\hline K1. Cause & $649(93.5 \%)$ & $45(6.5 \%)$ \\
\hline K2.Incubation period & $616(88.8 \%)$ & $78(11.2 \%)$ \\
\hline K3. Age group & $628(90.5 \%)$ & $66(9.5 \%)$ \\
\hline K4. Symptoms & $649(93.5 \%)$ & $45(6.5 \%)$ \\
\hline K5. Common cold, stuffy nose, runny nose, and sneezing are less common & $367(52.9 \%)$ & $327(47.1 \%)$ \\
\hline K6. Elderly more susceptible & $527(75.9 \%)$ & $167(24.1 \%)$ \\
\hline K7. Washing hands & $613(88.3 \%)$ & $81(11.7 \%)$ \\
\hline K8. Medical masks & $630(90.8 \%)$ & $64(9.2 \%)$ \\
\hline K9. Avoid going outside & $676(97.4 \%)$ & $18(2.6 \%)$ \\
\hline K10. Isolation and treatment & $654(94.2 \%)$ & $40(5.8 \%)$ \\
\hline K11. Transmission from contaminated dairy and meat & $275(39.6 \%)$ & $419(60.4 \%)$ \\
\hline K12. Fever & $544(78.4 \%)$ & $150(21.6 \%)$ \\
\hline K13. Spreads via respiratory droplets & $622(89.6 \%)$ & $72(10.4 \%)$ \\
\hline A1. COVID-19 is serious disease & $638(91.9 \%)$ & $56(8.1 \%)$ \\
\hline A2. Awareness is sufficient & $384(55.3 \%)$ & $310(44.7 \%)$ \\
\hline A3. COVID-19 can be controlled? & $428(61.7 \%)$ & $266(38.3 \%)$ \\
\hline A4. India can win against COVID-19 & $599(86.3 \%)$ & $95(13.7 \%)$ \\
\hline P1. Avoid going out & $659(95.0 \%)$ & $35(5.0 \%)$ \\
\hline P2. Wear mask & $677(97.6 \%)$ & $17(2.4 \%)$ \\
\hline P3. Avoid handshaking and hugging & $679(97.8 \%)$ & $15(2.2 \%)$ \\
\hline P4. Frequently wash hands & $675(97.3 \%)$ & $19(2.7 \%)$ \\
\hline P5. Use sanitizer and disinfectant & $661(95.2 \%)$ & $33(4.8 \%)$ \\
\hline P6. Use traditional medicine & $489(70.5 \%)$ & $205(29.5 \%)$ \\
\hline P7. Follow social distancing & $687(99.0 \%)$ & $7(1.0 \%)$ \\
\hline
\end{tabular}

\section{Knowledge outcome of COVID-19:}

The knowledge of participants was assessed by 13 questions on knowledge and the mean of total knowledge score was 10.73 (SD-1.82, Median-11.00) and Ranged from 10 to 12 (Table 2). More than $80 \%$ of the participants knew the cause, route of transmission, and susceptible age group of COVID 19. Common cold-like symptoms are less common was not known to $47 \%$ of the participants. The results suggested that $60.4 \%$ of the participants thought that contaminated dairy and meat can cause the transmission of COVID-19 (Table 1).

The knowledge score interpretation was done in terms of good, fair and poor and the study results suggested that the mean for good knowledge score was 11.78 ranged from 11 to 12 , for fair mean was 9.23 ranged from 9-10, for poor mean was 3 which ranged from 2-5 (Table 3). Distribution of the Participants in Terms of Knowledge Score Interpretation can suggest that more than half of the participants $(63.5 \%)$ had good knowledge though a very small proportion of participants which is $1.9 \%$ had poor knowledge.

Table 2: Total Scores of Knowledge, Attitude, and Practice about COVID-19 amongthegeneral population of India in terms of Mean, Median, and Range.

\begin{tabular}{lccc}
\hline KAP Total Scores & Range. & Mean \pm SD & Mian (IQR) \\
\hline K Score Total & $10.73 \pm 1.82$ & $11.00(10.00-12.00)$ & $0.0-13.0$ \\
\hline A Score Total & $2.95 \pm 0.98$ & $3.00(2.00-4.00)$ & $0.0-4.0$ \\
\hline P Score Total & $6.52 \pm 0.89$ & $7.00(6.00-7.00)$ & $0.0-7.0$
\end{tabular}

*IQR- Interquartile Range 
International Journal of Innovative Research in Science, Engineering and Technology (IJIRSET)

\title{
| e-ISSN: 2319-8753, p-ISSN: 2320-6710| www.ijirset.com | Impact Factor: 7.512|
}

\author{
||Volume 9, Issue 6, June 2020\|
}

Table 3: Level of knowledge about COVID-19 disease amongthegeneral population of India $(n=694)$

\begin{tabular}{|c|c|c|c|c|c|}
\hline \multirow{2}{*}{ K Score Total } & \multicolumn{3}{|c|}{ K Score Interpretation } & \multicolumn{2}{c|}{ Kruskal Wallis Test } \\
\cline { 2 - 5 } & Good & Fair & Poor & $\mathbf{X}^{\wedge} \mathbf{2}$ & p-value \\
\hline Mean (SD) & $11.78(0.72)$ & $9.23(0.97)$ & $3.00(2.00)$ & 509.336 & $<0.001$ \\
Median (IQR) & $12(11-12)$ & $10(9-10)$ & $4(2-5)$ & & \\
Range & $11-13$ & $6-10$ & $0-5$ & \\
$* \mathrm{X}^{\wedge}$ 2- Chi-square
\end{tabular}

Knowledge scores varied significantly across age, gender, marital status, education, employment status, income, and region. The study results suggested that the socio-demographic variables such as gender, education, employment status, monthly family income, region were significantly associated $(\mathrm{p}<0.05)$ with knowledge. However, marital status does not have a significant correlation (Table 4).

Table 4:Correlation of socio-demographics and the knowledge about COVID-19 amongthegeneral population of India(n=694)

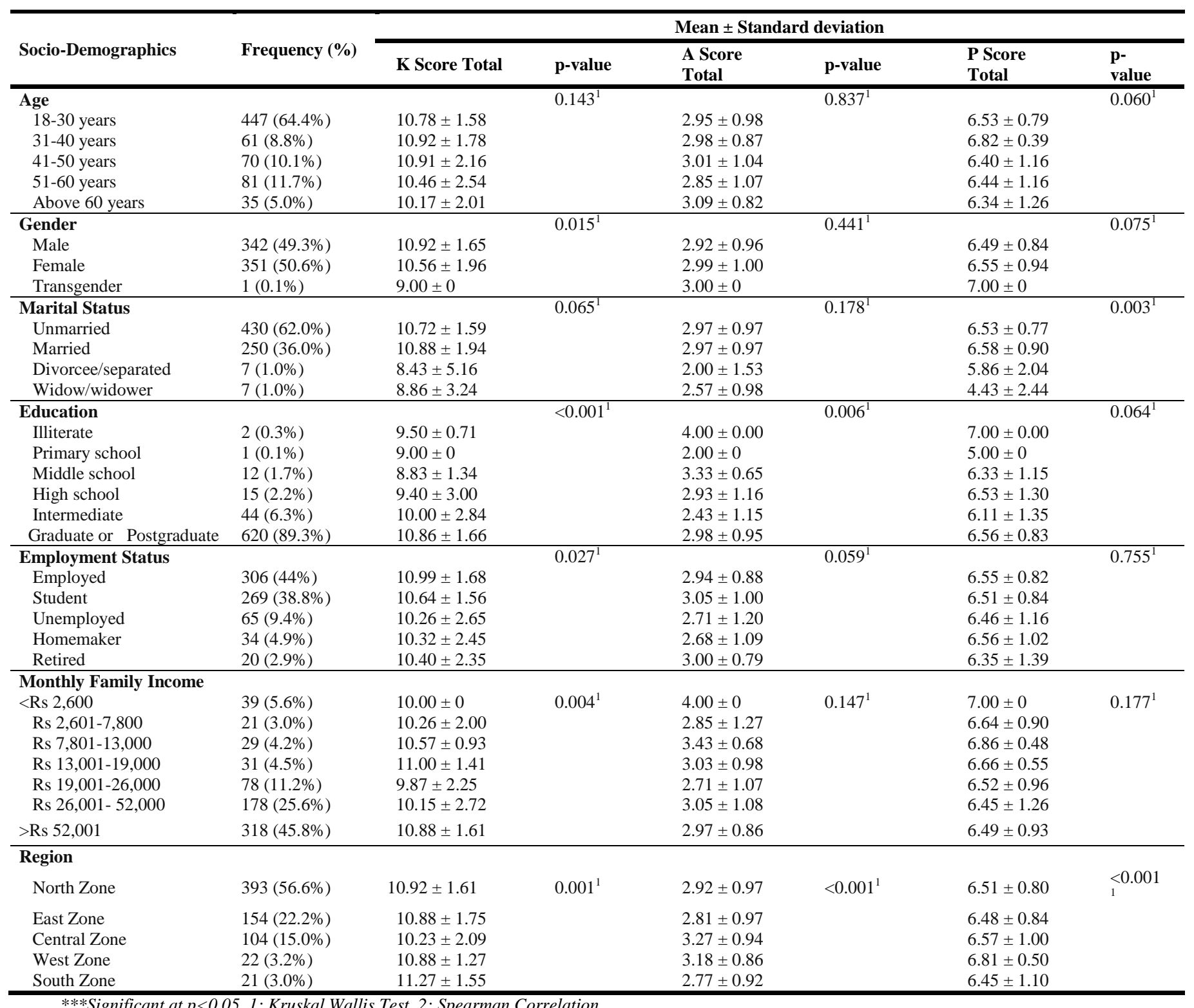




\section{| e-ISSN: 2319-8753, p-ISSN: 2320-6710| www.ijirset.com | Impact Factor: 7.512|}

\section{\|Volume 9, Issue 6, June 2020\|}

Good knowledge was persistent among all the age groups. Furthermore, poor knowledge was seen among participants of 18 to 30 years of age. Male had better knowledge than females on COVID-19 in India. Most of the participants who were graduate or postgraduate, had good knowledge whereas participants with illiterate to intermediate education background had fair knowledge. Most of the participants were employed and had better knowledge. There was a significant difference between the knowledge score interpretation in terms of $\mathrm{K}$ Score Total $\left(\mathrm{X}^{\wedge} 2=509.336, \mathrm{p}=\right.$ $<0.001$ ), with the median K Score Total being highest in the K Score Interpretation for Good knowledge (Table 5).

Table 5: Association between knowledge score interpretation and socio-demographics about COVID-19 disease amongthegeneral population of India $(n=694)$

\begin{tabular}{|c|c|c|c|c|}
\hline \multirow[b]{2}{*}{ Parameters } & \multicolumn{3}{|c|}{ Knowledge Score Interpretation } & \multirow[b]{2}{*}{ p-value } \\
\hline & $\begin{array}{c}\text { Good } \\
(n=441)\end{array}$ & $\begin{array}{c}\text { Fair } \\
(n=240)\end{array}$ & $\begin{array}{c}\text { Poor } \\
(n=13)\end{array}$ & \\
\hline $\operatorname{Age}^{* * *}$ & & & & $0.014^{1}$ \\
\hline 18-30 years & $277(62.8 \%)$ & $166(69.2 \%)$ & $4(30.8 \%)$ & \\
\hline $31-40$ years & $47(10.7 \%)$ & $12(5.0 \%)$ & $2(15.4 \%)$ & \\
\hline 41-50 years & $49(11.1 \%)$ & $19(7.9 \%)$ & $2(15.4 \%)$ & \\
\hline 51-60 years & $51(11.6 \%)$ & $26(10.8 \%)$ & $4(30.8 \%)$ & \\
\hline Above 60 years & $17(3.9 \%)$ & $17(7.1 \%)$ & $1(7.7 \%)$ & \\
\hline Gender*** & & & & $0.016^{2}$ \\
\hline Male & $235(53.3 \%)$ & $103(42.9 \%)$ & $4(30.8 \%)$ & \\
\hline Female & $206(46.7 \%)$ & $136(56.7 \%)$ & $9(69.2 \%)$ & \\
\hline Transgender & $0(0.0 \%)$ & $1(0.4 \%)$ & $0(0.0 \%)$ & \\
\hline Marital Status**** & & & & $<0.001^{2}$ \\
\hline Unmarried & $260(59.0 \%)$ & $167(69.6 \%)$ & $3(23.1 \%)$ & \\
\hline Married & $174(39.5 \%)$ & $69(28.7 \%)$ & $7(53.8 \%)$ & \\
\hline Divorcee/separated & $4(0.9 \%)$ & $1(0.4 \%)$ & $2(15.4 \%)$ & \\
\hline Widow/widower & $3(0.7 \%)$ & $3(1.2 \%)$ & $1(7.7 \%)$ & \\
\hline Education*** & & & & $<0.001^{2}$ \\
\hline Illiterate & $0(0.0 \%)$ & $2(0.8 \%)$ & $0(0.0 \%)$ & \\
\hline Primary school & $0(0.0 \%)$ & $1(0.4 \%)$ & $0(0.0 \%)$ & \\
\hline Middle school & $1(0.2 \%)$ & $11(4.6 \%)$ & $0(0.0 \%)$ & \\
\hline High school & $6(1.4 \%)$ & $8(3.3 \%)$ & $1(7.7 \%)$ & \\
\hline Intermediate & $23(5.2 \%)$ & $18(7.5 \%)$ & $3(23.1 \%)$ & \\
\hline Graduate or Post graduate & $411(93.2 \%)$ & $200(83.3 \%)$ & $9(69.2 \%)$ & \\
\hline Employment Status**** & & & & $<0.001^{1}$ \\
\hline Employed & $217(49.2 \%)$ & $85(35.4 \%)$ & $4(30.8 \%)$ & \\
\hline Student & $151(34.2 \%)$ & $117(48.8 \%)$ & $1(7.7 \%)$ & \\
\hline Unemployed & $39(8.8 \%)$ & $21(8.8 \%)$ & $5(38.5 \%)$ & \\
\hline Homemaker & $21(4.8 \%)$ & $11(4.6 \%)$ & $2(15.4 \%)$ & \\
\hline Retired & $13(2.9 \%)$ & $6(2.5 \%)$ & $1(7.7 \%)$ & \\
\hline Monthly Family Income*** & & & & $<0.001^{1}$ \\
\hline$<\operatorname{Rs} 2,600$ & $18(4.1 \%)$ & $20(8.3 \%)$ & $1(7.7 \%)$ & \\
\hline Rs $2,601-7,800$ & $12(2.7 \%)$ & $9(3.8 \%)$ & $0(0.0 \%)$ & \\
\hline Rs $7,801-13,000$ & $18(4.1 \%)$ & $11(4.6 \%)$ & $0(0.0 \%)$ & \\
\hline Rs $13,001-19,000$ & $13(2.9 \%)$ & $17(7.1 \%)$ & $1(7.7 \%)$ & \\
\hline Rs $19,001-26,000$ & $46(10.4 \%)$ & $25(10.4 \%)$ & $7(53.8 \%)$ & \\
\hline Rs $26,001-52,000$ & $121(27.4 \%)$ & $56(23.3 \%)$ & $1(7.7 \%)$ & \\
\hline$>$ Rs 52,001 & $213(48.3 \%)$ & $102(42.5 \%)$ & $3(23.1 \%)$ & \\
\hline Region*** & & & & $0.005^{1}$ \\
\hline North Zone & $261(59.2 \%)$ & $126(52.5 \%)$ & $6(46.2 \%)$ & \\
\hline East Zone & $81(18.4 \%)$ & $68(28.3 \%)$ & $5(38.5 \%)$ & \\
\hline Central Zone & $67(15.2 \%)$ & $37(15.4 \%)$ & $0(0.0 \%)$ & \\
\hline West Zone & $17(3.9 \%)$ & $5(2.1 \%)$ & $0(0.0 \%)$ & \\
\hline South Zone & $15(3.4 \%)$ & $4(1.7 \%)$ & $2(15.4 \%)$ & \\
\hline
\end{tabular}

***Significant at $p<0.05,1:$ Chi-Squared Test, 2: Fisher's Exact Test, 3: Kruskal Wallis Test 


\title{
| e-ISSN: 2319-8753, p-ISSN: 2320-6710| www.ijirset.com | Impact Factor: 7.512|
}

\author{
||Volume 9, Issue 6, June 2020\|
}

Attitude outcome of COVID-19:

The summary of attitude assessment on COVID-19 among the general population in India is shown in Table 1 which suggests that more than ninety percent of the participants considered COVID-19 as a serious disease. Participants showed a positive attitude regarding control of COVID-19 in the country. The results suggested that $44.7 \%$ of the participants' belief that awareness regarding COVID-19 is not sufficient in the society. The attitude of participants was assessed by 4 questions on attitude and the range of attitude score total was 2 to 4 and the mean was 2.95 (SD-0.98, Median-3.00) (Table 2). Attitude scores varied significantly across age, gender, marital status, education, employment status, income, and region. Though the attitude of participants towards COVID-19 was significantly associated $(\mathrm{p}<0.05)$ with the education and region (Table 4$)$.

Practice outcome of COVID-19:

The summary of practice assessment on COVID-19 among the general population in India is shown in Table 1. The participants suggested that they have adopted good hygiene practices from wearing a mask to frequent washing of hand. The study results suggested that ninety-nine percent (99\%) of the participants followed social distancing in their daily life. A little proportion of participants $(29.5 \%)$ did not consume any herbal products and traditional medicine to boost their immunity. The practice of participants was assessed by 7 questions on practice and the mean of practice score total was 6.52 (SD-0.89, Median-7.00) and Ranged from 6 to 7 (Table 2). Practice scores varied significantly across age, gender, marital status, education, employment status, income, and region. Thoughthe Practice of participants towards COVID-19 was significantly associated $(\mathrm{p}<0.05)$ with marital status and region. (Table 4)

The correlation among Knowledge, Attitude, and Practice of the general population in India can be seen in Figure 1. The scatterplot of Attitude vs Knowledge (I) and Knowledge vs Attitude (III) depicts a weak negative correlation whereas the scatterplot of Practice vs Knowledge (II), Practice vs Attitude (IV), Knowledge vs Practice (V), and Attitude vs Practice (VI) depict a weak positive correlation. The scatterplot of Practice vs Attitude (IV) and Attitude vs Practice (VI) showed that the correlation was statistically significant (rho $=0.24, \mathrm{p}=<0.001$ ).

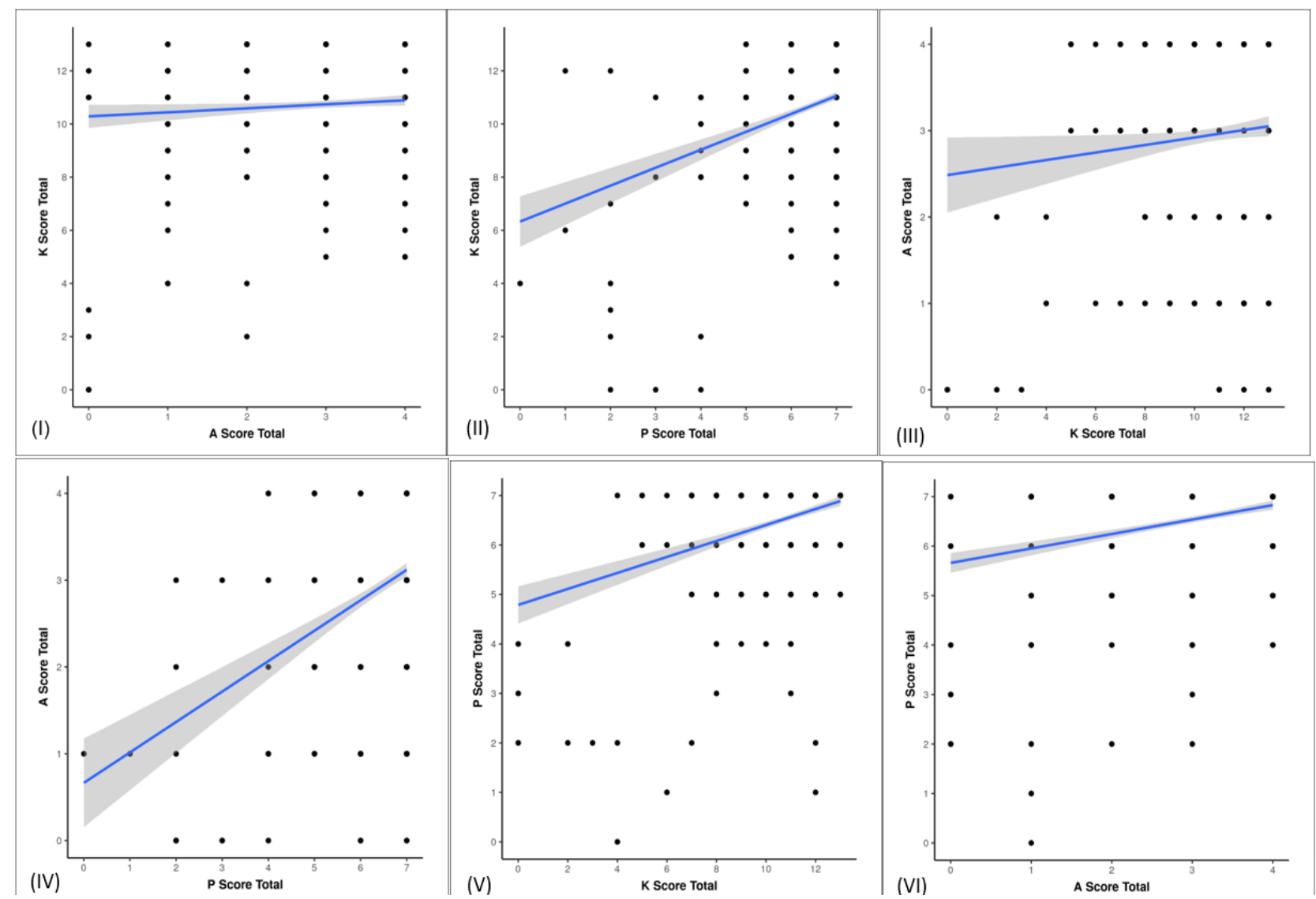

Figure 1- Scatter plot correlation among Knowledge (K), Attitude (A), and Practice (P) of the general population in India: (I): A vs K, (II): P vs K, (III): K vs A, (IV): P vs A, (V): K vs P, (VI): A vs P 
India is the second most populated country in the world [14], thus a large number of citizens are at greater risk of transmission and mortality by COVID-19 in India. Particularly among the elderly and those with chronic ailments. Worldwide efforts to stop the spread of the virus have been made. These efforts are based on the general public's understanding of the disease, which is mainly regulated by their knowledge and attitude. Taking this into account it was necessary to know the level of knowledge among citizens about COVID-19, their attitude towards COVID-19, and the practice they have adopted to prevent themselves from getting infected, all these aspects are covered in our study. As of 21June 2020, lockdown in India is only constrained to containment zone so to prevent the upsurge of COVID-19 cases it is necessary that citizens have good knowledge and attitude, and bring it to their practices of daily life.

In view of our findings, the correct rate of $83 \%$ on the knowledge questionnaire suggested that most participants were well-informed about COVID-19. Our scores were a bit similar to a study conducted in Iran [15]. The high correct rate for COVID-19 information in the general population of India is may be due to the high availability of governmentprovided information about the virus since the outbreak began. Another reason is that $89.3 \%$ of participants were graduates. Scores were significantly equal for both males and females; this was contrary to a study conducted in China ${ }_{11}$ which showed that females were more knowledgeable about COVID-19. Educated and married had significantly higher knowledge scores. In our study, most of the participants $(93.5 \%)$ knew the causative agent, $97.5 \%$ of the participants knew about the prevention and control required, and $90.5 \%$ of the participants knew about the susceptible age group for COVID 19.

Participants in the study, exhibit good KAP towards COVID-19, compared to a study conducted in Thailand on the bordered population during the early outbreak period[16]. In Thailand, $73.4 \%$ had poor knowledge of disease prevention and control, while in our study only $1.9 \%$ of the participants had poor knowledge moreover $28.5 \%$ had poor attitudes toward the disease, while in our study $26.2 \%$ had poor attitudes. The main reason for these differences can be due to the difference in time of the study conducted. Our study was conducted when cases were rising and initiatives by the government were taken to increase awareness of the population, while in Thailand study was conducted during the early outbreak period when the number of cases was not that high.

Regarding attitudes, participants had a positive attitude towards the control of COVID-19 in the country and $90 \%$ of the participants considered COVID-19 as a serious disease. The attitude score of the participants was 74\%. Interestingly our study suggests that females had better attitude scores than males. Though participants believed that awareness regarding COVID-19 is not sufficient in society, this may be due to the increasing number of COVID-19 cases in the country. The attitude of participants was significantly associated with education and region.Comparatively $61.7 \%$ of the participants admit that COVID-19 cannot be controlled in India this is contrary to the study conducted in Tanzania on KAP towards COVID-19 where $96 \%$ of the participants had an attitude that COVID-19 can be controlled in their country[17]. Our study suggested that attitude and practice are correlated which means a positive attitude will lead to positive practices by the citizen.

Regarding practice, $93.2 \%$ of the participants in our study have adopted preventive measures to control COVID-19. Moreover, our study suggests that participants wear a mask (97.6\%), frequently wash hands (97.3\%), avoid handshaking and hugging $(97.8 \%)$, and avoid going out $(95 \%)$. Thus, this suggests that the citizens of India have adopted major practices to prevent the contraction of the virus. Participants in the age group of 31 to 40 had better practice scores than participants of other age groups. A study conducted in Bangladesh on KAP of COVID-19 showed that $87.97 \%$ of participants followed social distancing in their daily routine Interestingly, in our study, $99 \%$ of the participants followed social distancing in their daily routine[18]. Even social distancing is an effective measure to control the spread of the disease and to limit the cases of COVID-19 in the country. Moreover, our study also suggested that knowledge was highly associated with the practice of participants thus the citizens of the country adopted social distancing and it was considered an effective measure to halt the cases of the disease in the country. A paper suggested that traditional medicine from Homeopathy and Ayurveda are immunity boosters to fight against coronavirus disease [19]. Certainly, in our study, 70.5\% of the participants consume Herbal products and traditional medicines to boost their immunity. Experts have said that resurgence of COVID 19 cases may take place following the relaxation implemented for lockdown. To prevent this, the practices need to be instilled in the citizen [20]. The major limitation of this study is that the survey was restricted to people with internet access.

Our study concludes that the overall population had good knowledge, positive attitude, and adopted the practices to prevent the disease during the pandemic. Furthermore, males tend to be superior in knowledge in contrast females tend to be superior in attitude and practice. People with low knowledge about COVID-19 need to be targeted, in order to promote their positive attitude and to adopt safe practices. The government should create tools to increase awareness and adoption of safe practices during this hard time. 
REFERENCES

[1] Novel Coronavirus (2019-nCoV) Situation Report - 1. Who.int. 2020. Available from: https://www.who.int/docs/default-source/coronaviruse/situation-reports/20200121-sitrep-1-2019ncov.pdf?sfvrsn=20a99c10_4

[2] 2019-nCoV outbreak is an emergency of international concern. Euro.who.int. 2020. Available from: http://www.euro.who.int/en/health-topics/emergencies/pages/news/news/2020/01/2019-ncov-outbreak-is-anemergency-of-international-concern

[3] Coronavirus disease 2019 (COVID-19), Situation Report -52. Who.int. 2020. Available from: https://www.who.int/docs/default-source/coronaviruse/situation-reports/20200312-sitrep-52-covid19.pdf?sfvrsn=e2bfc9c0_4

[4] Novel Coronavirus Disease (COVID-19), Situation Update Report -20, India. Who.int. 2020. Available from: https://www.who.int/docs/default-source/wrindia/situation-report/india-situation-report-20.pdf?sfvrsn=ce03fd22_2

[5] COVID-19 Coronavirus Pandemic- Worldometer. Worldometers.info. 2020. Available from: https://www.worldometers.info/coronavirus/

[6] Kaushik S, Kaushik S, Sharma Y, Kumar R, Yadav JP. The Indian perspective of COVID-19 outbreak. VirusDisease. 2020; Available from: https://doi.org/10.1007/s13337-020-00587-X

[7] Dahab M, Zandvoort VK, Flasche S, Warsame A, Spiegel PB, Waldman J, \& Checchi F. COVID-19 control in lowincome settings and displaced populations: what can realistically be done? | LSHTM. London Sch Hyg Trop Med. 2020;1-10. Available from: https://www.lshtm.ac.uk/newsevents/news/2020/covid-19-control-low-income-settingsand-displaced-populations-what-can

[8] Wong G, Liu W, Liu Y, Zhou B, Bi Y, Gao GF. MERS, SARS, and Ebola: The Role of Super-Spreaders in Infectious Disease. Cell Host Microbe. 2015;18(4):398-401. Available from: http://dx.doi.org/10.1016/j.chom.2015.09.013

[9] Tachfouti N, Slama K, Berraho M, Nejjari C. The impact of knowledge and attitudes on adherence to tuberculosis treatment: a case-control study in a Moroccan region. Pan Afr Med J. 2012;12:52. Epub 2012 Jun 28. PMID: 22937192; PMCID: PMC3428172.

[10] Hung LS. The SARS epidemic in Hong Kong: what lessons have we learned? J R Soc Med. 2003 Aug;96(8):374-8. doi: 10.1258/jrsm.96.8.374. PMID: 12893851; PMCID: PMC539564.

[11] Zhong BL, Luo W, Li HM, Zhang QQ, Liu XG, Li WT, Li Y. Knowledge, attitudes, and practices towards COVID-19 among Chinese residents during the rapid rise period of the COVID-19 outbreak: a quick online cross-sectional survey. Int J Biol Sci. 2020 Mar 15;16(10):1745-1752. doi: 10.7150/ijbs.45221. PMID: 32226294; PMCID: PMC7098034.

[12] Johns Hopkins Coronavirus Resource Center. 2020. Available From: https://coronavirus.jhu.edu/

[13] Emerging respiratory viruses, including COVID-19: methods for detection, prevention, response and control. OpenWHO. 2020. Available from: https://openwho.org/courses/introduction-to-ncov

[14] Population, India | Data. Data.worldbank.org. $2020 . \quad$ Available from: https://data.worldbank.org/indicator/SP.POP.TOTL?locations=IN

[15] Erfani A, Shahriarirad R, Ranjbar K, Mirahmadizadeh A \&Moghadami M. Knowledge, Attitude and Practice toward the Novel Coronavirus (COVID-19) Outbreak: A Population-Based Survey in Iran. [Preprint]. Bull World Health Organ. E-pub: 30 March 2020. doi: http://dx.doi.org/10.2471/BLT.20.256651

[16] Srichan P, Apidechkul T, Tamornpark R, Yeemard F, Khunthason S, Kitchanapaiboon S, Wongnuch P, Wongphaet A, Upala P. Knowledge, Attitude and Preparedness to Respond to the 2019 Novel Coronavirus (COVID-19) Among the Bordered Population of Northern Thailand in the Early Period of the Outbreak: A Cross-Sectional Study. SSRN Electron J. 2020. Available at SSRN: https://ssrn.com/abstract=3546046 or http://dx.doi.org/10.2139/ssrn.3546046

[17] Hussain A, Garima T, Singh BM, Ram R, Tripti RP. Knowledge, attitudes, and practices towards COVID-19 among Tanzanian Residents: A quick online cross-sectional survey. Asian J Med Sci. 2020;11(3):6-11. doi: https://doi.org/10.1101/2020.04.26.20080820

[18] Haque T, Hossain KM, Bhuiyan MMR, Ananna SA, Chowdhury SH, Ahmed A, Rahman MM. Knowledge, attitude and practices (KAP) towards COVID-19 and assessment of risks of infection by SARS-CoV-2 among the Bangladeshi population: An online crosssectional survey. Res Sq. 2020;1-21. Available from: https://europepmc.org/article/ppr/ppr156164

[19] Prajapati S, Gv NK. SARS-CoV-2 pandemic: an opportunity for Indian traditional medicines (AYUSH). 2020;13(3):103-5. Available from: https://medcraveonline.com/IJCAM/IJCAM-13-00502.pdf

[20] Rana M, Kundapur R, Maroof A, Chaudhari V, Kadri A, Kumar P, Zodpey S, Agrawal A, Bapat N. Way ahead- Post Covid-10 Lockdown in India. Indian J Comm Health. 2020;32(2-Special Issue):175-183. Available from: https://www.iapsmupuk.org/journal/index.php/IJCH/article/view/1465 